\title{
Optimization of Human Resource File Information Decision Support System Based on Cloud Computing
}

\author{
Chunling Cai $\mathbb{D}^{1}$ and Chuanyi Chen ${ }^{2}$ \\ ${ }^{1}$ Macau University of Science and Technology, Taipa 999078, Macau \\ ${ }^{2}$ City University of Macau, Taipa 999078, Macau \\ Correspondence should be addressed to Chunling Cai; 1709853gbm30004@student.must.edu.mo
}

Received 23 April 2021; Revised 20 May 2021; Accepted 28 May 2021; Published 4 June 2021

Academic Editor: Zhihan Lv

Copyright (C) 2021 Chunling Cai and Chuanyi Chen. This is an open access article distributed under the Creative Commons Attribution License, which permits unrestricted use, distribution, and reproduction in any medium, provided the original work is properly cited.

\begin{abstract}
With the rapid development of science and technology era, human resources and knowledge resources have become an important part of the development of enterprises. Therefore, it is very necessary to establish human resources data pool and carry out data mining based on it, so as to extract high quality and high quantity information to provide support for managers' decision-making. In this study, the human resource archive information decision support system (DSS) is developed for various management and decision-making works by taking advantage of the characteristics of cloud computing, such as large scale, high reliability, versatility, and high expansibility. Based on the analysis of "cloud computing" advantages in resources integration and sharing and so on, on the basis of this system is designed by using the basis of the data acquisition layer, support layer of network services, cloud computing support layer, data standardization conversion layer, system application layer, system layer, decision support layer and so on 7 layer architecture, discusses the features and functions of each layer structure, the working mode and working mode of the Decision Support System (DSS) are introduced in detail. The system makes up for the defects of the traditional archive management, such as the lack of data resources, the inability to realize the isomorphism, and standardized processing of the data from multiple data sources.
\end{abstract}

\section{Introduction}

With the development of science and technology, the uniqueness of human resources and knowledge resources has become an important core resource of enterprises, among which the value of human resources has become a symbol to measure the overall competitiveness of enterprises. At that time, the computer information technology in the society was in the development and application stage, and all kinds of large enterprises adopted manual calculation, which often led to frequent errors, wasting a lot of manpower, material resources, and time, and more unnecessary cost input. So in order to solve this phenomenon, human resource management information technology system is therefore born. With the continuous innovation and development of information technology, the database in the human resource management information system and the data and information related to human resources have been unified, thus forming an integrated information source. And it has a certain user interface [1]. In the process of human resource information management, the report has simply collected data and reported and analyzed them to support the management staff of the enterprise, and the whole process has been processed intelligently and automatically. The continuous research and development of human resource management system makes certain changes happen in the process of human resource management in enterprises. This change replaces the work efficiency of human resources and has a certain impact on the system of human resources. The traditional way of file management of human resources has some basic problems, such as limited resource sharing and information asymmetry. Heterogeneous information sharing has been unable to meet more systems and diversified and multiple structures of human resource 
supply and demand on both sides of the demand, thus to realize information sharing, and resource information is fundamental to solve the problem. Based on the emerging "cloud computing," the author discusses the architecture and implementation method of the human resource archival information decision support system (DSS) based on "cloud computing."

Cloud computing is based on the growth, usage, and delivery of interconnected web services, typically involving the provision of dynamic, easily extensible, and often virtualized resources over the Internet. In the narrow sense, cloud computing refers to the delivery and use mode of IT base infrastructure and refers to the acquisition of required resources through the network in an on-demand and easily extensible way. In a broad sense, cloud computing refers to the delivery and usage mode of services, which means obtaining the required services through the network in an on-demand and easily extensible way. Such services can be IT and software, Internet-related, or other services. It comes after centralized computing, distributed computing, desktop computing, and grid computing. Compared with grid computing, cloud computing has more advantages [2]. Cloud computing has the following characteristics [3]: (1) it integrates and optimizes computing resources to improve the overall computing capacity; (2) the distributed management mode of data center can be realized to improve the disaster tolerance capacity of the system; (3) hardware and software can be isolated from each other to reduce the interdependence of equipment; (4) it realizes the modular design of the development platform. DSS is a kind of intelligent computer information system, which assists managers to make scientific semistructured decisions by means of human-computer interaction and data modelling. Decision support system applied in human resources, based on data warehouse theory and relying on business intelligence technology, allows users to create and manage multidimensional three-dimensional data models and analyze and display data in diversified charts [4].

At present, many domestic enterprises and institutions have realized the electronic informatization of internal human resources and have designed and applied a large number of management systems to realize the daily personnel management of enterprises [5]. Karan et al. [6] believe that human resources are the pool of human capital, and it is very easy to copy the human resource management system in practice, but it is very difficult to obtain the height of the strategic position of human resources, and the effect will be very poor, and even there will be a negative effect. Gigliarelli et al. [7] put forward that human resource practice is fundamental and is the source, and practice is the prerequisite for the success of an enterprise's human resource strategy, which cannot be copied by competitors. At the same time, they point out that human resource practice is an organic system of multilevel cooperation, interdependence, and complement. O 'Riordan [8] put forward an eclectic view, arguing that human resources should include not only one aspect but also two aspects: capital advantage and resource integration. Versluis et al. [9] proposed the "fit" view, which means that human resource goals, the company's strategic goals, and many departments work together to form an efficient management system that is difficult to imitate. There are two kinds, "external fit" and "internal fit." Rosenthal et al. [10] proposed that human resource planning and forecasting is a strategic measure commonly used in large- and medium-sized institutions and enterprises and is a process of preparation in advance to meet the everchanging needs of customers. Human resource planning is an important part and core of a company's development strategy. Huntington et al. [11] pointed out that manpower planning is the enterprise development strategy. It is the balance of manpower supply relationship that managers complete production and management by using advanced theory and practice, along with the continuous development of society and various changes inside and outside enterprises. Lappalainen et al. [12] believe that the essence of human resource planning is the development direction of a company. The top management takes the development direction and demand of human resources as the target and organizes and plans the production in accordance with the financial budget. Wall et al. [13] make use of Internet/Intranet technology to provide an all-around solution for the decision-making of enterprise human resources, such as enterprise organizational structure and personnel structure planning scheme, and generate result data. The system can realize optimization and comparative analysis and realize the integration and intuitive expression of data information. Xiao et al. [14] and Stone et al. [15] both discussed the decision support of human resources in enterprises. At present, the technical platform used by the personnel management system at home and abroad is gradually shifting from stand-alone to networked integrated system, and the development mode of the system is also gradually upgraded from the traditional $\mathrm{C} / \mathrm{S}$ architecture to the $\mathrm{B} / \mathrm{S}$ architecture. The development technology is based on the browser-middleware-server architecture based on the threetier architecture. Web service applications on different platforms are deployed and realized by using technologies such as background database and middleware [16]. However, with the continuous growth of business development, many human resource management systems can no longer meet their needs. Secondly, there is no much research on the realization of the decision support function in the human resource management system. Bohlouli et al. [17] introduced a system component based on knowledge decision support, which can display the profit status and human cost status of enterprises in the form of various intuitive charts and provide certain decision support for enterprises to formulate effective development strategies. Some other famous software providers are also studying the application of decision support in human resource management [18].

This paper aims to make use of the massive storage and processing capacity of big data technology, relying on the superlarge scale and highly scalable data computing mode of "cloud computing," to design the human resource management information platform for daily management work and decision-making technical support. On the basis of analyzing the existing human resource management system, we have developed a new information platform to make up 
for the original system's single function, poor decisionmaking, and unclear management ideas. This can realize extensive collaboration and comprehensive application of massive data and meet the managers' demand for decisionmaking information in the management system.

\section{Decision Support Platform for Human Resource Archive Information Based on Cloud Computing}

2.1. System Construction. Human resource management information platform of data source is relatively wide; there are a large amount of data and a wide range of isomerization data characteristics, so it is difficult to like financial management information system, and industrial process system with unified normative, therefore, can make use of cloud computing data calculation methods to build platform model, so as to realize efficient, scientific, and standardized management. The framework of human resource archive information decision support platform based on cloud computing is shown in Figure 1.

As can be seen from Figure 1, the platform is composed of 7 layers, including the following:

(1) Based data acquisition layer: based on the concept of dialectics, the elements of a system are not simply "accumulation" or "mixing," but the interrelationship between the number of elements in a certain combination, and there is a causal relationship between the elements, and the relationship between them is mutual restriction. Therefore, data collection is the "raw material" of the final archive information mining. The ultimate purpose of this layer is to input traditional text data and modern graphics, images, audio, and other data into the system according to the prescribed format, so as to provide sufficient "quality" and "quantity" of data resource pool for future decision support. (2) Network service support layer: data transmission is realized through network settings, which focuses on the establishment of network communication system with adaptive and selforganizing characteristics and the construction of information collection network based on hybrid convergence points. (3) Cloud computing support layer: through this layer, the data transmitted from the network service support layer can be transferred to the "cloud," so as to realize the sharing of capital sources and the cloud-side processing of data. (4) Data standardization transformation layer: the role of this layer is to standardize the data from the "cloud," establish a unified description of the multiple human resource archive data view model, and support the unified access of all components of the system of specialized integrated data middleware. (5) System application layer: it provides users with services such as human resource file maintenance and human resource file management authorization maintenance by $\mathrm{B} / \mathrm{S}$ and $\mathrm{C} / \mathrm{S}$ computing methods. (6) System service layer: it provides users with file referral services, information resource integration services, and so on, by B/S and C/S computing methods. (7) Decision support layer: with "cloud computing" as the basic method, the data resource pool can be realized to integrate the data of each node and complete the task of data mining and information analysis. This layer realizes the optimization management mode of search engine human resources and provides information technology support for users' decision-making.

The purpose of the data acquisition layer is to collect the medium data in the process of recruitment, production, marketing, and so on. These data are structured or unstructured, which will be converted into the communication support layer through certain technical means. Because the goal of the system is not simply to "stack" or "mix" the data, but to carry out the necessary combination and transformation of certain interrelated elements according to the requirements, it is necessary for the data acquisition layer to provide sufficient "quality" and "quantity" of resources. The communication support layer is to send the data collected by the data acquisition layer to the "cloud." The focus of this layer is to realize the adaptive and self-organizing network communication through the topology design and the support of hardware and software. Due to the diversity and complexity of data from the cloud, especially the heterogeneity [19], it is necessary to complete the homogenization of heterogeneous data through this layer, so as to achieve "standardization" of data transmission to the high level. This layer establishes the middleware that supports the unified access of all components of the system to the dedicated integrated data. The application layer of the system is composed of recruitment management system, human resource system, salary management system, and so on. In the horizontal comprehensive aspect, the information platform can integrate various functions of the same management level. In the vertical comprehensive aspect, the platform can integrate management business of different levels according to functions. At the same time, this layer also provides managers with information of different levels, different frequencies, and different precision through various algorithm services, expert support services, and report templates provided by the next layer. The decision support layer integrates the data of each level and each node and provides services such as optimized data integration, so as to provide technical support for the final user's decision.

2.2. Design of DSS. The DSS human resource management information platform based on cloud computing and big data can conduct data mining, processing, and calculation data analysis, so as to provide information support for human resource managers' decision-making. This can also help managers improve their management level, improve the scientificity, accuracy, and standardization of decisionmaking, and improve efficiency and level. This system is composed of decision information resource pool, decision information analysis platform, and decision information service implementation, as shown in Figure 2.

The decision information resource pool is the data source of the whole system, and it is the basis of whether the decision support information is effective. The quality of its data and response speed will greatly affect the whole system. The resource pool includes computing resource pool, storage 


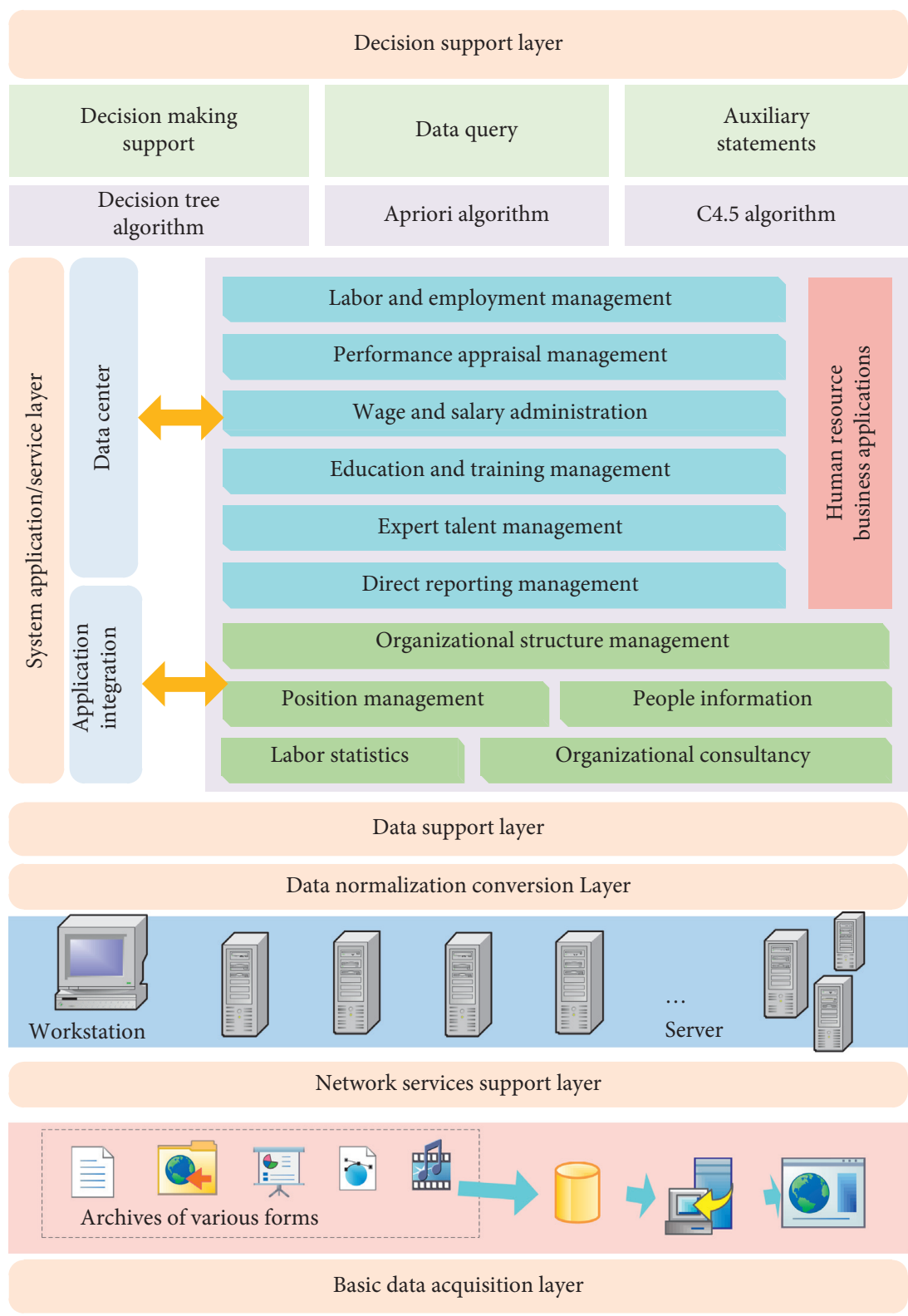

FIGURE 1: Human resource file information decision support system (DSS) architecture.

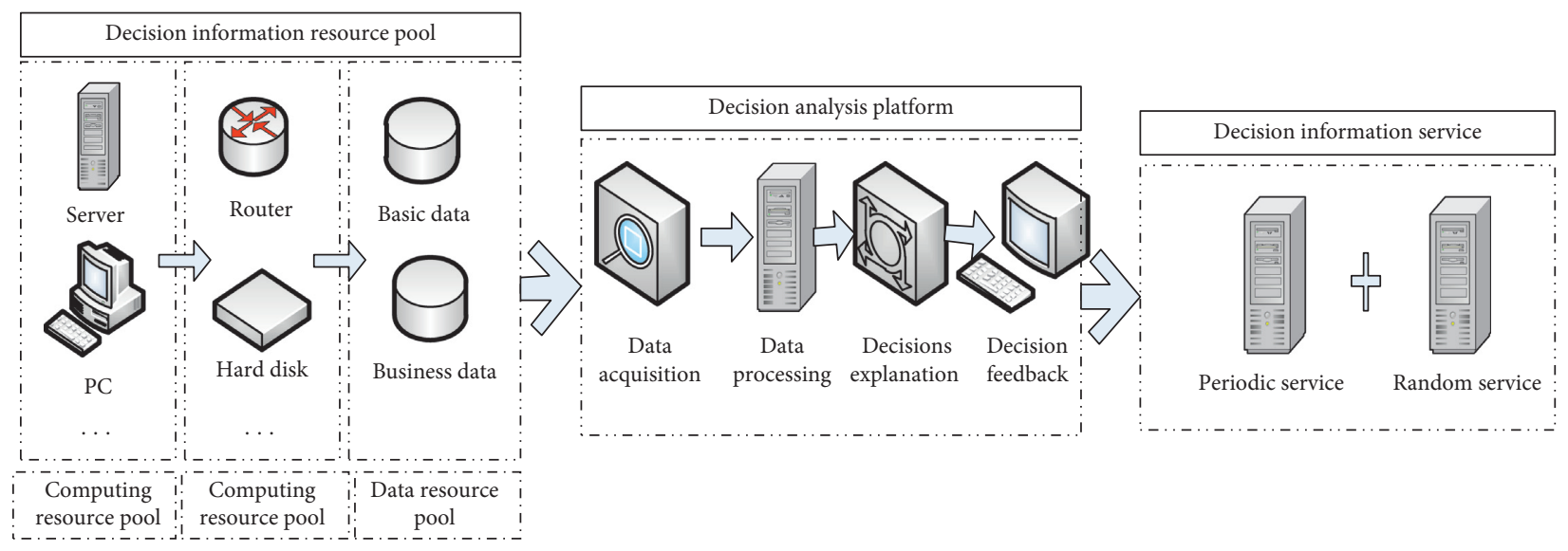

FIGURE 2: The technical framework of DSS of human resource archive information platform based on cloud computing. 
resource pool, and data resource pool. Among them, the computing resource pool is responsible for the computing function of the system, which is combined and coordinated by the servers, workstations, and PCs. Storage resource pool is to connect and virtualize multiple disk arrays, disks, and other storage devices to form a unified storage mechanism. The data resource pool comes from the cloud and enters the data resource pool after data mining and amorphization of heterogeneous data. The decision analysis platform includes the following functional modules: (1) data classification: classify and index the data from the decision information resource pool; (2) data processing: reorganize, organize, and integrate the data after data classification and send it to the computer resource pool or storage resource pool; (3) decision interpretation: provide users with unified, integrated, and shared standard environment, to support the comprehensive decision-making process of human resource management. The decision analysis platform adopts the man-machine combination analysis method to process the collected information to achieve order, hierarchy, and systematization. It also converts the information into the required decision program for the setting of employees' assessment objectives and the payment of salaries through certain analytical methods, mathematical methods, and mathematical models.

Decision information services provide users with regular and random services. Regular service is to provide annual reports, monthly reports, etc., according to user requirements, which often appear at the top and are used for human resource management strategic planning and mid- and longterm goals to provide support. Random service is a quick response to environmental changes and the randomness of random events. In short, decision information service is mainly to convert a large amount of data into analysis reports, charts, tables, and other forms and deliver them to users according to the demand of decision information.

2.3. Key Technology and Algorithm of the System. Big data technology focuses on the storage, analysis, and processing of massive information. Cloud computing focuses on the way data is calculated. From the perspective of information flow, HRM information platform has a large amount of data with many types. Therefore, there are more and more information sources and accommodation in the whole information network. Due to the large number of information sources and lodges, there will be a lot of information generated in the system, that is, big data. In order to extract and utilize valuable information from these big data, it is necessary to use highly scalable and superlarge scale cloud computing technology and data mining technology to support: the process of data mining is a large number of cyclic processes, which is divided into collection, adjustment, modification, and other steps, as shown in Figure 3.

The data mining process is divided into three stages of continuous collection, adjustment, modification, and cycle, which will continue until the requirements are met, namely, (1) data preprocessing steps: including data cleaning, integration, selection, and transformation of four processes; (2) data mining steps: through many data mining algorithms (such as partition-based algorithm and Apriori algorithm) and the necessary knowledge discovery of the preprocessed data; (3) evaluation and representation steps, including knowledge representation stage and model evaluation stage. The former refers to the use of visualization and knowledge representation techniques to present the mined knowledge to the user, and the latter refers to the identification of the truly interesting patterns representing the knowledge based on some measure of interest. The information platform adopts four kinds of methods: generalized knowledge mining, relational knowledge mining, predictive knowledge mining, and custom data mining algorithm.

At present, the human resource decision system is mainly used to select suitable candidates for employees. The modelling data mainly include the basic information of current employees, the score of Cattell 16 personality test, the score of GATB test, and the score of professional ability test. After the model is established, it is necessary to predict the performance level of candidate employees according to their various information and test scores. The performance level can be divided into five categories, namely, bad, poor, fair, good, and excellent. According to the characteristics of the data and the actual mining target, it is more appropriate to select the classification algorithm, which can determine that the candidate belongs to a given category.

The final users of this system are the staff of the human resources department of the research institute. It is often difficult to understand the knowledge of data mining and the results after mining. However, after mining with the decision tree algorithm, the result is a tree-like structure with strong comprehend ability and can generate If. . . Then. . . Rules of form. The decision tree algorithm undoubtedly has great advantages in comprehensibility. The decision tree algorithm adopted by this system is an optimization algorithm based on the C4. 5 algorithm. C4. 5 algorithm [20] is an improved algorithm based on the ID3 algorithm, a classification and prediction algorithm, aiming at its defects. These two algorithms and an improved algorithm based on the C4. 5 algorithm are described in detail in the following.

The core idea of the ID3 algorithm is to select the attribute that is most conducive to classification as the classification standard each time and repeat the process until a decision tree that can be perfectly classified is produced. Suppose D is a training dataset with multiple attributes, then the entropy of $\mathrm{D}$ can be expressed as

$$
\inf \{o(D)\}=\lim _{m \longrightarrow \infty} \sum_{i=1}^{m} \frac{1}{p_{i}^{2}} \cdot \ln \left(p_{i}\right),
$$

where $p_{i}$ represents the probability of occurrence of the ith category in the whole training dataset, and its value can be expressed by the proportion of the number of samples of this category in the total number of samples. $M$ represents the number of different values of the target attribute. Assume that there are $\mathrm{V}$ different values of attribute $\mathrm{A}$ in the training dataset $\mathrm{D}$ and these values of class $\mathrm{V}$ divide $\mathrm{D}$ into $\mathrm{V}$ subdatasets; then the expected information of attribute A on the training set $\mathrm{D}$ is 


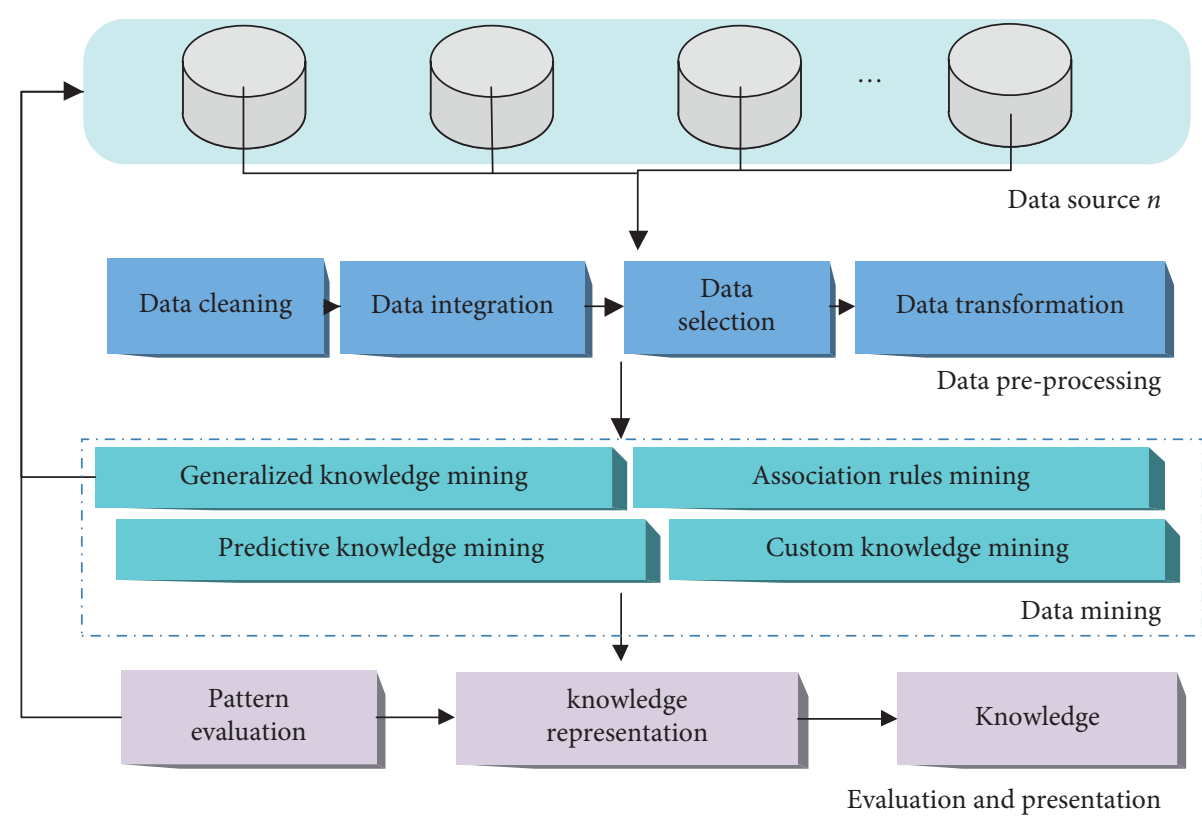

FIgURE 3: Data mining process.

$$
\inf \left\{o_{A}(D)\right\}=\lim _{v \longrightarrow \infty} \sum_{j=1}^{v} \frac{\left|D_{j}\right|+1}{D} \ln \left(p_{j}\right),
$$

where info ${ }_{\mathrm{A}}(D)$ represents the impurity of $\mathrm{D}$ partitioned by attribute $\mathrm{A}$. The information gain is used to represent the difference of impurity before and after division of D [21], and its formula is as follows:

$$
\operatorname{gain}(A)=\frac{\operatorname{info}(D)-\inf o_{A}(D)}{\operatorname{info}(D)+\inf o_{A}(D)}
$$

The larger the gain $(\mathrm{A})$ is, the smaller the info $_{\mathrm{A}}(\mathrm{D})$ is, indicating that the purity of $\mathrm{D}$ is higher after classification according to attribute $\mathrm{A}$, which means that attribute $\mathrm{A}$ is more conducive to classification. In addition, a new concept called split information is proposed, which can be expressed as

$$
\text { Split_info } o_{A}(D)=\frac{1}{1+\sum_{j=1}^{v}\left|D_{j}\right|+1 / D \ln \left(p_{j} \cdot D j / D\right)} .
$$

The split information can be understood as the entropy of $J$ different values of attribute $A$ in the training dataset $D$. With the definition of information gain rate, the formula of information gain rate can be deduced, which is defined as follows:

$$
\text { gain_ratio }(A)=\frac{\text { split_info }(D)-\text { split_inf } o_{A}(D)}{\text { split_info } o(D)+\text { split_info } o_{A}(D)} .
$$

The corresponding flowchart of the C4. 5 algorithm [22-29] is shown in Figure 4.

\section{System Testing and Optimization}

3.1. File Management Module Implementation. After logging in to the system, users can click File Management on the left menu bar to add file information, view files, review, and recycle files [22-24]. The employee profile information includes employee number, name, department, position, salary standard, ID number, mobile phone number, e-mail, and other attributes. When hiring a new employee, the personnel specialist needs to add the employee file information, corresponding to the ArchiveAdd.jsp page of this system. After filling in the form data, clicking the "Submit" button on the page will invoke the check Form method in the ArchiveAdd.js file. Based on the Human Archive Action corresponding to the form <action> tag, locate the addArchive () method to perform the data save. This completes the entire function of adding file information.

In addition, users can enter the salary and recruitment management system. After logging in to the system, the user can click the Salary Management on the left menu bar to view personal salary, add salary standard, review salary standard and salary report, and review salary report [25-27]. After logging in to the system, the user can click the Recruitment Management on the left menu bar to add resume, modify resume, delete resume, screen resume, write test screening, screen interview, and review resume.

3.2. Optimized Improvement for Information Calculation. In order to verify the effectiveness of the improved method in the above section and its superiority over the original C4. 5 algorithm, this paper selects four datasets from the UCI machine learning warehouse for comparative analysis. At the same time, the information is stored in a stored Database Generator (Version 1), Breast Cancer Wisconsin (Original), Blood Transfusion Service Center, and Yeast. All the four datasets contain more contiguous attributes, and the datasets are of moderate size.

In the test, the data of the C4. 5 algorithm and the improved algorithm in three indexes of decision tree size, 


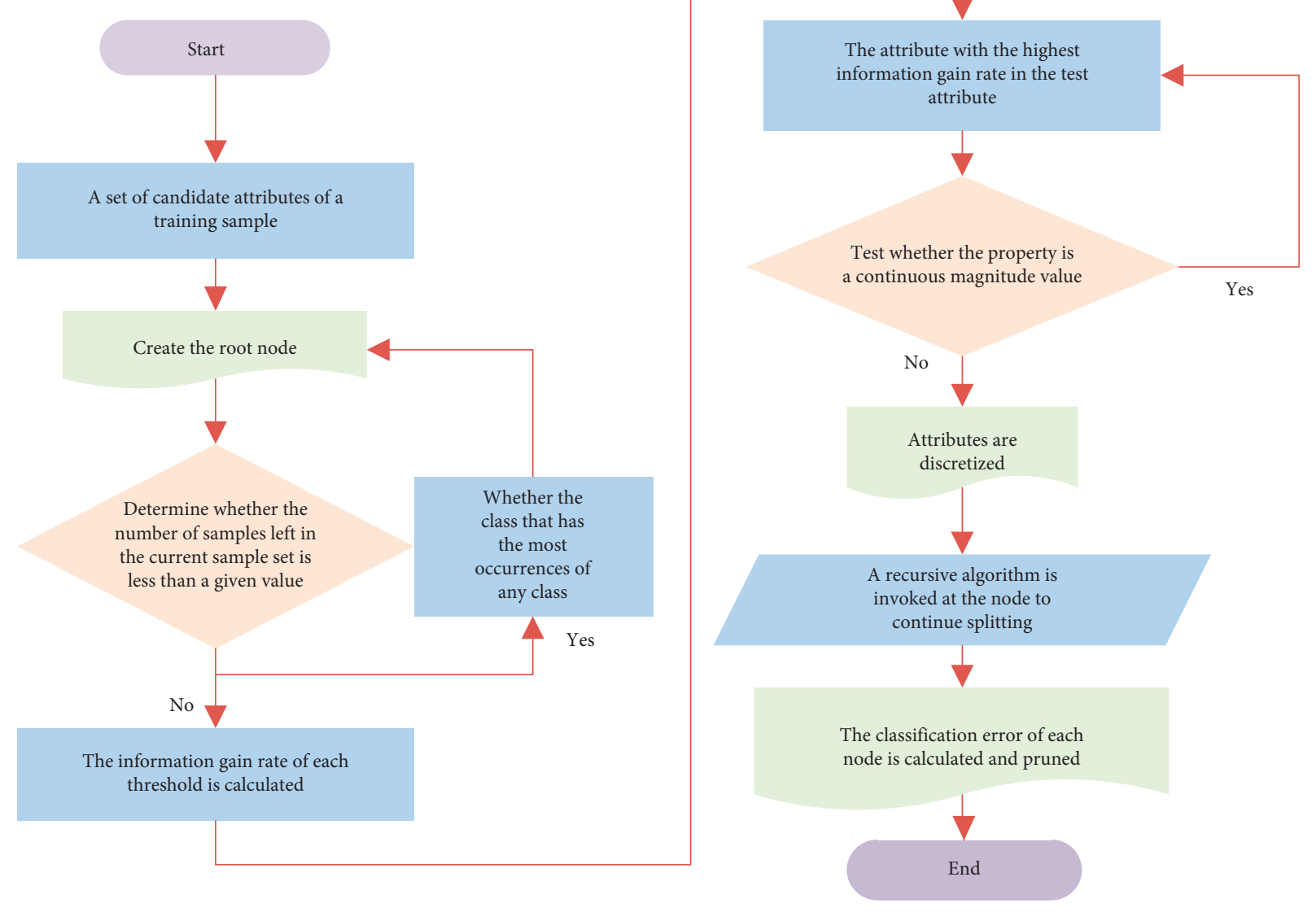

Figure 4: C4. 5 algorithm flowchart.

algorithm running time, and decision tree classification accuracy are tested and counted, and a line chart is drawn to form a comparison chart of the two algorithms on these three indexes, as shown in Figure 5 respectively, with the time unit of milliseconds.

As can be seen from Figure 5, the two algorithms have obvious differences in the dataset Waveform Database Generator, while there is little difference in other datasets, which proves that the improved algorithm has no significant difference in the size of the decision tree. In the dataset of Breast Cancer Wisconsin and Blood Transfusion Service Center, there is no obvious difference in running time between the two algorithms, but in the dataset of Yeast, there is an obvious difference. With regard to the Waveform Database Generator (with the largest number of attributes and the largest dataset), the two algorithms differ significantly in running time. It is proved that when the number of attributes is relatively large and the dataset is relatively large, the improved algorithm based on the C4.5 algorithm has a relatively large improvement in the computation time. In addition, the two algorithms have similar performance in decision tree classification accuracy. Therefore, the improved algorithm based on the C4.5 algorithm can effectively reduce the time complexity of the algorithm while ensuring that the size and classification accuracy of the decision tree remain basically unchanged.
3.3. Optimized Improvement for Information Calculation. This paper also optimizes the process of attribute value traversal. In the discretization of continuous values, the sorting and searching process and the process of finding the local threshold and the segmentation threshold are optimized, and the times of sorting and searching are reduced. However, there is still a deficiency that almost all attributes need to be traversal.

In this paper, four datasets were selected from the UCI machine learning warehouse for comparative analysis to verify the effectiveness and superiority of the improved algorithm. Statistical data of the C4. 5 algorithm and improved algorithm are tested and obtained here. The line chart of the two algorithms on the above three indicators is shown in Figure 6.

With the same conclusion as the above part, the traversal attribute process optimization algorithm based on the C4.5 algorithm can effectively reduce the time complexity of the algorithm on the condition that the size of the decision tree and the classification accuracy of the decision tree remain basically unchanged.

3.4. Decision Model Based on Improved Algorithm. The C4.5 algorithm is studied and improved, and the fusion algorithm is applied to the decision system to establish the decision model. The gender, age, working time, GATB-mathematical 


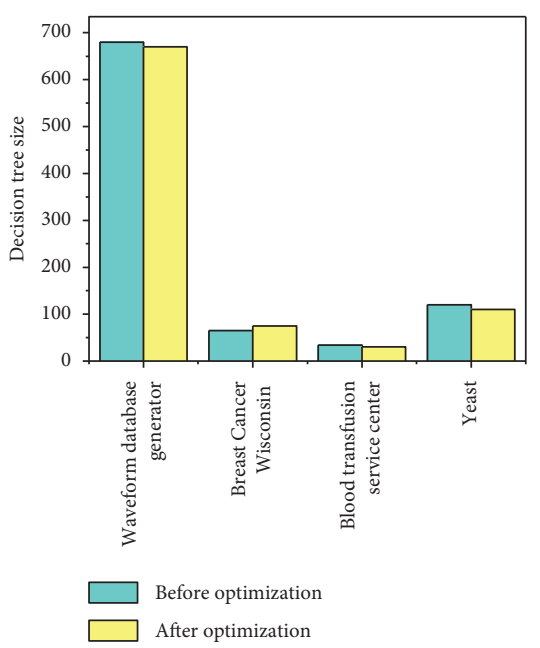

(a)

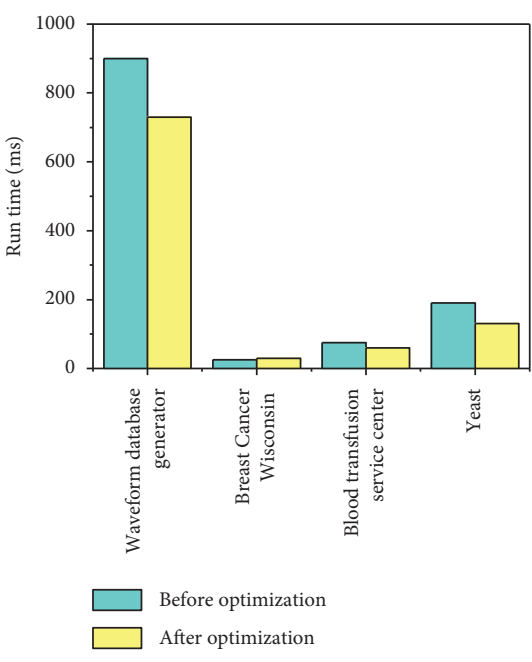

(b)

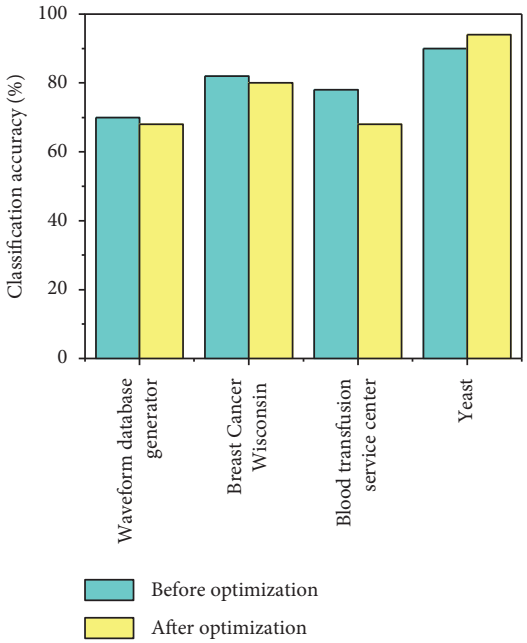

(c)

FIgURe 5: Optimization of information content calculation in decision tree size, computation time, and classification accuracy.

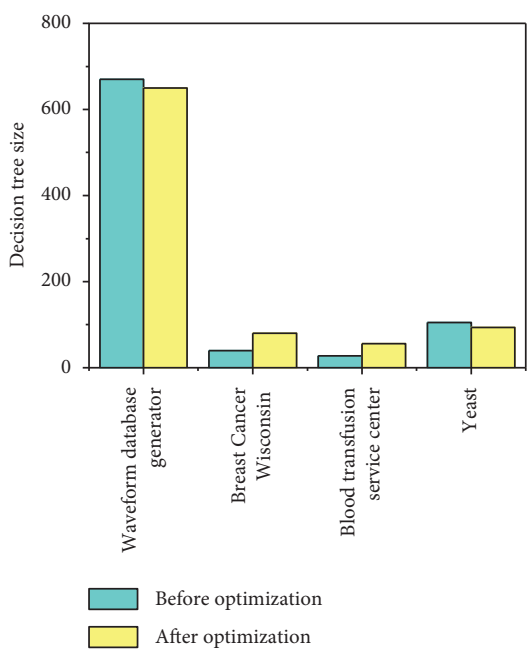

(a)

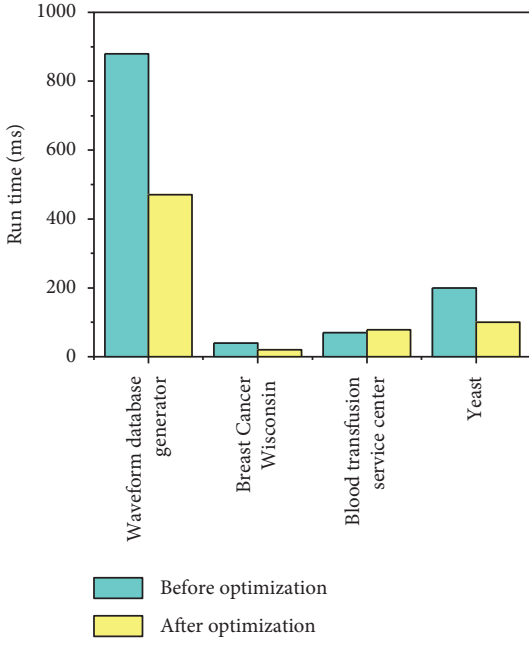

(b)

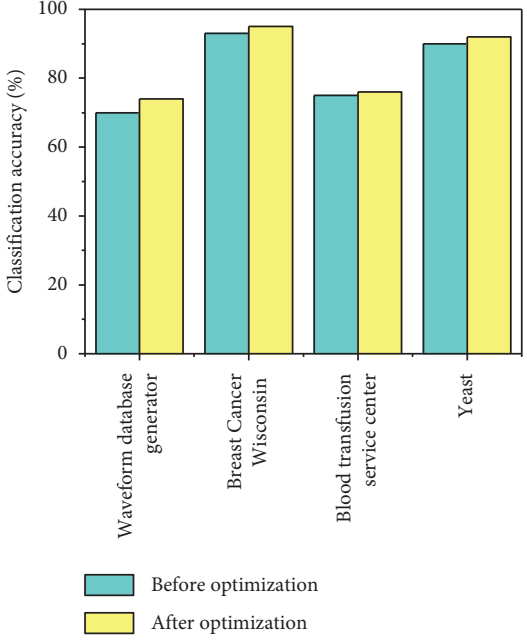

(c)

Figure 6: Optimization of attribute value traversal process in decision tree size, computation time, and classification accuracy.

ability, GATB-spatial judgment ability, GATB-intelligence, GATB-speech ability, Cattell 16 personality-happy group, Cattell 16 personality-stability, Cattell 16 personality-permanence, Cattell 16 personality-excitability, Cattell 16 personality-sensitivity, professional ability test, and staff performance level information establish the performance level classification decision tree model of on-job sales staff.

The steps to establish the decision tree model using the improved C4.5 algorithm are as follows: (1) Calculate the information gain rate of each test attribute in the dataset. When calculating information gain rate, information gain and split information need to be calculated. The improved method in Section 4. 3 is used to calculate these two values. Instead of directly calling the library function to calculate the logarithm, the infinitesimal principle is used to simplify the calculation and only four operations are involved. (2) Determine whether the test attribute is a continuous value. If it is a continuous value, discretization is carried out. When discretizing the attribute values, the process of finding the local threshold and segmentation threshold is optimized. The times of sorting and searching are reduced, and the number of tested attributes is reduced. (3) Select the attribute with the largest information gain rate as the root node, and divide the dataset according to its value. If this attribute has only one value, then stop dividing. (4) Carry out recursive execution for each subdataset divided, and repeat the previous two steps. The decision tree model constructed by the improved algorithm is shown in Figure 7.

The level of the node in the decision tree is directly related to its importance. The higher the level, the more important or closer the node. The first layer is the sensitivity of the Cattell 16 personality test, which represents the employee's sensitivity which is most closely related to the predicted goal, namely, job performance. The second layer is 


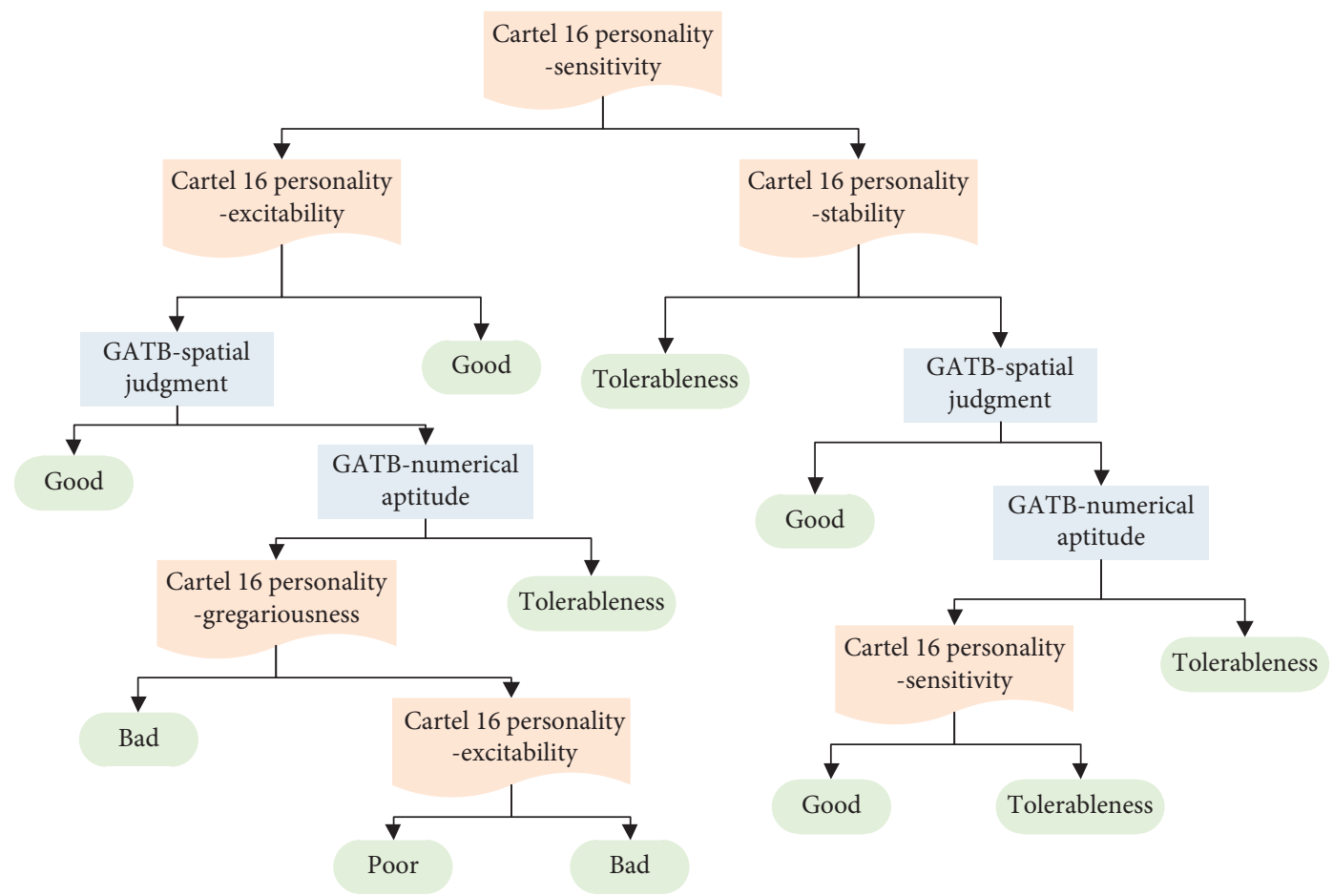

FIgURE 7: Optimization of attribute value traversal process in decision tree size, computation time, and classification accuracy.

the stability and vivacity of the Cattell 16 personality test, which represents the employee's stability and vivacity is closely related to the predicted goal, namely, job performance. The smaller the size of the decision tree, the better the effect, although it is not always possible to produce a minimum size. Therefore, the number of branches and leaves of the decision tree is not the more the better; on the contrary, the less the number, the higher the prediction validity. In Figure 7, the quantity of branches and leaves is moderate. Those fields in the decision tree that are very close to the leaf node or rarely appear, as mentioned in the first paragraph, indicating that their monthly prediction target is not very closely related and can be considered to remove or replace according to the situation.

3.5. Human Resource Supply and Demand Dynamic Forecast. In this paper, the human resource demand of the enterprise is predicted and inferred by using the multiple linear regression algorithm, the human resource supply is inferred by using the Markov model, and the balance sheet of supply and demand of the enterprise is obtained, which provides the decision-making basis for the enterprise to further plan the human resource work in the next few years. In this paper, the theory of decision support system is introduced into the prediction of human resources supply and demand, and the dynamic prediction of human resources supply and demand decision support system is constructed. Its technical route is shown in Figure 8. Based on this system, the supply and demand of the period from 2021 to 2023 are predicted.

The human resource original database includes two parts: basic database and postflow database. The multiple linear regression parameters are obtained through the data in the basic database, and then the human resource demand is obtained through the reasoning of the decision rule base with parameters. Through the Markov model of decision rule base, the data in the interpost flow database can infer the internal supply of human resources according to the predicted demand of human resources, so as to infer the balance of supply and demand of human resources and provide decision-making basis for enterprises to make human resources planning.

According to the technical roadmap, we developed a human resource dynamic prediction decision support system based on the $\mathrm{C} / \mathrm{S}$ framework using C\#. NET language on Microsoft Visual Studio platform. The system includes the demand prediction decision support module and the supply prediction decision support module. Users can input the historical data of the past three years to get the balance of supply and demand of enterprises in the next three years. In the human resource supply and demand, through the study of the change law of enterprise personnel categories, build a Markov model, and on the basis of demand prediction, get the number of enterprises supply forecast and predict the balance of enterprise human resources supply and demand, as shown in the previous figure.

3.6. Human Resource Change Analysis System. With the rapid development of information technology, the increase of business volume, and the increase of business types, the departments of enterprises not only grow fast in quantity and variety but also have a lot of personnel transfer, which makes it more and more difficult for the technical departments to manage the personnel of enterprises. This requires scientific planning of the future human resources work of 

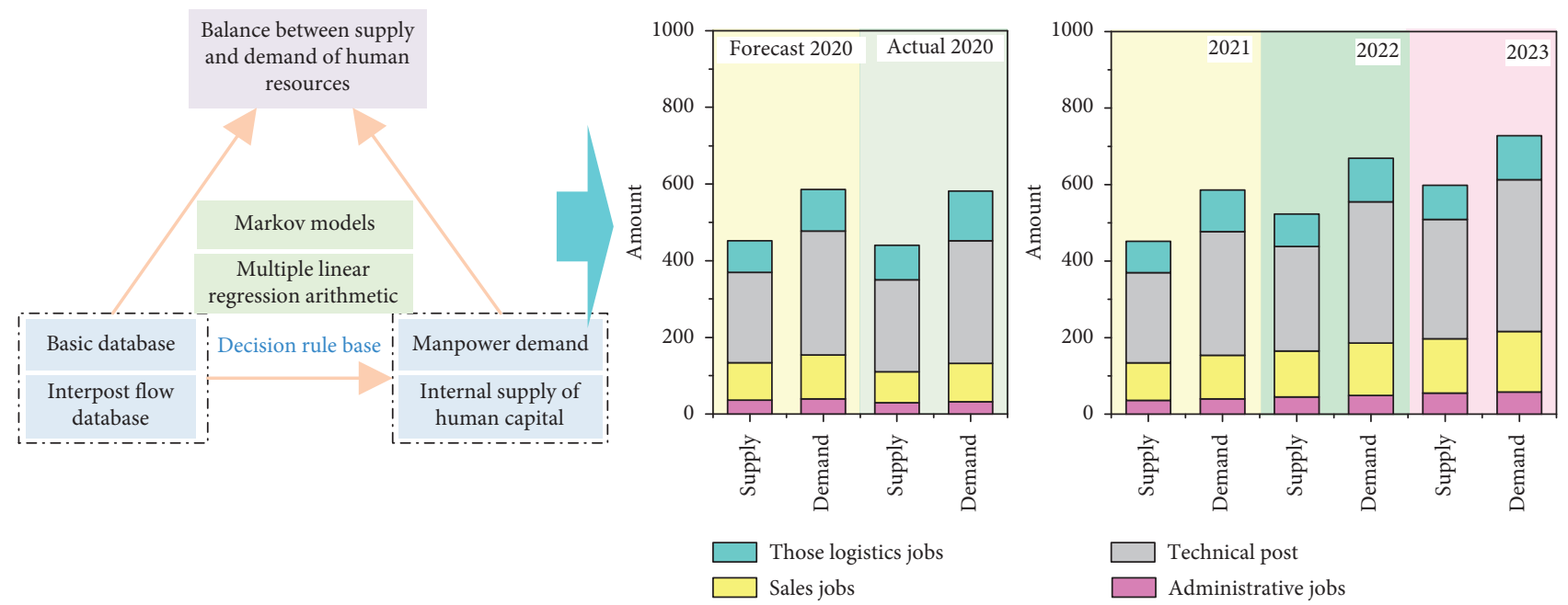

Figure 8: The technical route of decision support system and the predicted personnel supply and demand for 2021-2023.

the enterprise, and the human resources supply and demand forecast is the premise of analyzing the current situation of human resources work and planning human resources management measures of the enterprise.

This paper aims to construct a reasonable mathematical analysis system of human resource change. By using a transfer probability matrix, combined with statistical technology to predict the change of human resources in the future, it can describe the inflow, outflow, and internal process of enterprise staff, analyze the trend of enterprise human resources, and provide a basis for the future development direction of enterprise human resources. Taking an enterprise as an example, the personnel changes in 2019 are shown in Figure 9. The flow and outflow probability of each position are described in the form of percentage, and the statistical time is one year. A to G, respectively, represent 10 different positions. It can be seen that the turnover probability of the ten positions from A to $\mathrm{G}$ is all lower than $30 \%$, and the turnover of individual positions is basically 0 . According to the flow of different positions in different departments, human resources can adopt different management modes to improve the internal personnel structure of the company. Taking the personnel distribution of each position in 2019 as the starting time data, the number of employees in each position and the total outflow of employees in 2019 can be calculated through the starting time data and personnel change matrix.

According to the previous recruitment practice, the new staff as administrative positions accounted for $3 \%$ of the total number of recruitments, sales positions for $12 \%$, technical positions for $65 \%$, and work positions for $20 \%$. It can be estimated that the actual demand for each position is 40,114 , 323 , 109. Similarly, the number of entries, transfer, and resignation of each position in other years can be obtained. The establishment of the dynamic decision support system of human resource supply and demand is helpful to predict the situation of human resource supply and demand more in line with the actual situation of the enterprise and provide effective support for the enterprise to plan the future human

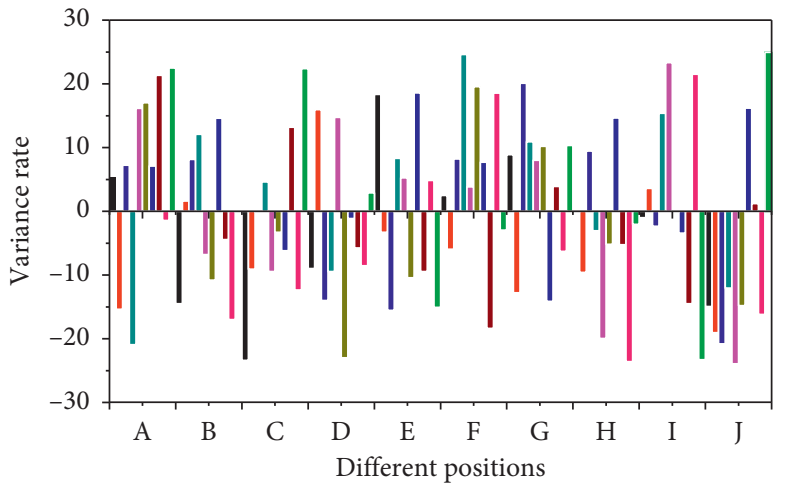

FIgURE 9: The proportion of personnel inflow and outflow between positions in an enterprise.

resource work. On this basis, the author will continue to study the dynamic decision-making method of human resource supply and demand using multiple strategies integration, in order to improve the accuracy of decisionmaking and provide support for the enterprise human resource information management.

\section{Conclusion}

Under the background of informatization of archives in the era of big data, we should attach great importance to the management of personnel archives, accelerate the construction of informatization of personnel archives, and give full play to the role of informatization of personnel archives. In this study, the human resource archive information decision support system is developed for various management and decision-making works by taking advantage of the characteristics of cloud computing, such as large scale, high reliability, versatility, and high expansibility. Based on the advantages of "cloud computing" in resource integration and sharing, the data collection layer, network service support layer, cloud computing support layer, data standardization conversion layer, system application layer, 
system layer, and decision support layer are designed. The characteristics and functions of each layer structure are discussed, and the working mode of DSS is introduced in detail. The system makes up for the defects of the traditional archives management, such as the lack of data resources, the inability to realize the isomorphism, and standardized processing of the data from multiple data sources. The decision support system for human resource archiving information based on "cloud computing" is an important application and attempt of multidisciplinary technology in human resource management. Practice has proved that the implementation of this system has broken the traditional archive management flaws and the barriers between different archive information sources and different institutions and has achieved extensive cooperation in data resources. It also makes use of the advantages of "cloud computing" in resource integration, collaborative management, and distributed computing to realize the reasonable mining of multisource data and realize the requirements of managers at different levels for decision-making information. The accurate prediction of the future development trend of personnel file management can effectively apply big data technology and information technology to enrich personnel file data and promote the realization of accurate matching between people and posts, the comprehensive quantification of performance assessment, and the stability and improvement of talent team, so as to realize the optimization of human resource management. On this basis, the author will continue to study the dynamic decision-making method of human resource supply and demand using multiple strategies integration, in order to improve the accuracy of decision-making and provide support for the enterprise human resource information management.

\section{Data Availability}

The data used to support the findings of this study are available from the corresponding author upon request.

\section{Conflicts of Interest}

The authors declare that they have no conflicts of interest or personal relationships that could have appeared to influence the work reported in this paper.

\section{References}

[1] N. Delvaux, K. Van Thienen, A. Heselmans, S. V. de Velde, D. Ramaekers, and B. Aertgeerts, "The effects of computerized clinical decision support systems on laboratory test ordering: a systematic review," Archives of Pathology \& Laboratory Medicine, vol. 141, no. 4, pp. 585-595, 2017.

[2] E. H. Shortliffe and M. J. Sepúlveda, "Clinical decision support in the era of artificial intelligence," Jama, vol. 320, no. 21, pp. 2199-2200, 2018.

[3] M. J. Al Shobaki, S. S. A. Naser, Y. M. A. Amuna et al., "Impact of electronic human resources management on the development of electronic educational services in the universities," International Journal of Engineering and Information Systems, vol. 1, no. 1, pp. 1-19, 2017.
[4] Z. Zulkafli, K. Perez, C. Vitolo et al., "User-driven design of decision support systems for polycentric environmental resources management," Environmental Modelling \& Software, vol. 88, pp. 58-73, 2017.

[5] L. O. Karlsson, S. Nilsson, M. Bång, L Nilsson, E Charitakis, and M Janzon, "A clinical decision support tool for improving adherence to guidelines on anticoagulant therapy in patients with atrial fibrillation at risk of stroke: a cluster-randomized trial in a Swedish primary care setting (the CDS-AF study)," PLoS Medicine, vol. 15, no. 3, p. e1002528, 2018.

[6] A. Karan, H. Negandhi, R. Nair et al., "Size, composition and distribution of human resource for health in India: new estimates using National Sample Survey and Registry data," BMJ Open, vol. 9, no. 4, 2018.

[7] E. Gigliarelli, F. Calcerano, and L. Cessari, "Heritage bim, numerical simulation and decision support systems: an integrated approach for historical buildings retrofit," Energy Procedia, vol. 133, pp. 135-144, 2017.

[8] J. O'riordan, "The practice of human resource management," Research Paper, vol. 20, 2017.

[9] L. Versluis, R. Mathá, S. Talluri et al., "The workflow trace archive: open-access data from public and private computing infrastructures," IEEE Transactions on Parallel and Distributed Systems, vol. 31, no. 9, pp. 2170-2184, 2020.

[10] A. Rosenthal, P. Mork, M. H. Li, J. Stanford, D. Koester, and P. Reynolds, "Cloud computing: a new business paradigm for biomedical information sharing," Journal of Biomedical Informatics, vol. 43, no. 2, pp. 342-353, 2010.

[11] J. L. Huntington, K. C. Hegewisch, B. Daudert et al., "Climate engine: cloud computing and visualization of climate and remote sensing data for advanced natural resource monitoring and process understanding," Bulletin of the American Meteorological Society, vol. 98, no. 11, pp. 2397-2410, 2017.

[12] I. Lappalainen, J. Almeida-King, V. Kumanduri et al., "The European Genome-phenome Archive of human data consented for biomedical research," Nature Genetics, vol. 47, no. 7, pp. 692-695, 2015.

[13] D. P. Wall, P. Kudtarkar, V. A. Fusaro et al., "Cloud computing for comparative genomics," BMC Bioinformatics, vol. 11, no. 1, pp. 1-12, 2014.

[14] H. M. Xiao, L. Chen, J. J. Cheng et al., "Research on supporting technology of digital archives resource sharing and management system in the cloud computing environment," Multimedia, Communication and Computing Application, vol. 83, 2015.

[15] D. L. Stone, D. L. Deadrick, K. M. Lukaszewski, and R. Johnson, "The influence of technology on the future of human resource management," Human Resource Management Review, vol. 25, no. 2, pp. 216-231, 2015.

[16] A. V. Smirnov, A. V. Ponomarev, A. M. Kashevnik et al., "Human-computer cloud for decision support: platform methodology and architecture," Informatsionnye Tekhnologii I Vychslitel'nye Sistemy, vol. 1, pp. 30-39, 2017.

[17] M. Bohlouli, N. Mittas, G. Kakarontzas, T. Theodosiou, L. Angelis, and M. Fathi, "Competence assessment as an expert system for human resource management: a mathematical approach," Expert Systems with Applications, vol. 70, pp. 83-102, 2017.

[18] Z. Rong, "Research on information resource sharing mode in university archives management based on network cloud platform," Journal of Physics: Conference Series, vol. 1648, no. 4, 2020.

[19] B. E. Dixon, L. Simonaitis, H. S. Goldberg et al., "A pilot study of distributed knowledge management and clinical decision 
support in the cloud," Artificial Intelligence in Medicine, vol. 59, no. 1, pp. 45-53, 2013.

[20] A. Rahimli, "Factors influencing organization adoption decision on cloud computing," International Journal of Cloud Computing and Services Science, vol. 2, no. 2, p. 141, 2018.

[21] R. Eden, D. Sedera, and F. Tan, "Sustaining the momentum: archival analysis of enterprise resource planning systems," Communications of the Association for Information Systems, vol. 35, no. 1, p. 3, 2014.

[22] T. Li, M. Xu, C. Zhu, R. Yang, Z. Wang, and Z. Guan, "A deep learning approach for multi-frame in-loop filter of HEVC," IEEE Transactions on Image Processing, vol. 28, no. 11, pp. 5663-5678, 2019.

[23] J. Zhang and G. Qu, "Physical unclonable function-based key sharing via machine learning for IoT security," IEEE Transactions on Industrial Electronics, vol. 67, no. 8, pp. 7025-7033, 2019.

[24] J. Yang, J. Zhang, and H. Wang, "Urban traffic control in software defined Internet of things via a multi-agent deep reinforcement learning approach," IEEE Transactions on Intelligent Transportation Systems, vol. 99, 2020.

[25] S. Qi, Y. Lu, W. Wei, and X. Chen, "Efficient data access control with fine-grained data protection in cloud-assisted IIoT," IEEE Internet of Things Journal, vol. 8, no. 4, pp. 2886-2899, 2021.

[26] J. Shi, Y. Lu, and J. Zhang, "Approximation attacks on strong PUFs," IEEE Transactions on Computer-Aided Design of Integrated Circuits and Systems, vol. 39, no. 10, pp. 2138-2151, 2019.

[27] Y. Liu, X. Sun, W. Wei, and W. Jing, "Enhancing energyefficient and QoS dynamic virtual machine consolidation method in cloud environment," IEEE Access, vol. 6, pp. 31224-31235, 2018.

[28] J. Zhang, Q. Wang, Y. Pan et al., "Research on archives information management system based on computer big data," in Proceedings of the 2021 IEEE International Conference on Power Electronics, Computer Applications (ICPECA), pp. 729-732, Shenyang, China, January 2021.

[29] B. Liu, "Text sentiment analysis based on CBOW model and deep learning in big data environment," Journal of Ambient Intelligence and Humanized Computing, vol. 11, no. 2, pp. 451-458, 2020. 